\title{
Response of Caudate Neurons to Stimulation of Intrinsic and Peripheral Afferents in Normal, Symptomatic, and Recovered MPTP-treated Cats
}

\author{
David S. Rothblat and J. S. Schneider \\ Department of Neurology, Hahnemann University School of Medicine, Philadelphia, Pennsylvania 19102
}

Cat caudate nucleus (CD) neurons were tested for changes in spontaneous activity, response to peripheral sensory stimuli (tactile, auditory, and visual), and electrical stimulation of monosynaptic afferents (pericruciate cortex and nucleus centralis lateralis) in normal cats and in the same cats after induction of and spontaneous recovery from parkinsonism induced by 1-methyl-4-phenyl-1,2,3,6-tetrahydropyridine (MPTP). After normal baseline data were collected, cats were given MPTP $(7.5 \mathrm{mg} / \mathrm{kg}, 5-7 \mathrm{~d})$ to induce a parkinsonian syndrome consisting of rigidity, akinesia, and decreased orienting to sensory stimuli. During this symptomatic period, the mean spontaneous activity of $C D$ units increased (6.20 spikes/sec vs 2.25 spikes/sec in normal cats). In these same animals, the percentage of units responding to peripheral sensory stimulation was significantly decreased (compared to normal) while the percentage of units responding to electrical stimulation of monosynaptic afferents increased.

By 6 weeks after MPTP administration, cats had recovered gross motor and sensorimotor function and $C D$ unit recordings were reinitiated. In functionally recovered animals, all electrophysiological measures returned to levels resembling those seen in normal animals. These data suggest that the processing of peripheral sensory information is an important part of basal ganglia function and that the sensory responsiveness of the CD may reflect the overall motor condition of the animal. The changes observed in the responsiveness of $C D$ neurons to direct electrical stimulation of monosynaptic afferents may indicate that the defect in the processing of polysynaptic sensory information observed in the striatum in parkinsonian animals may be occurring, at least in part, extrastriatally.

IKey words: caudate nucleus, sensory responsiveness, parkinsonism, cats, 1-methyl-4-phenyl-1,2,3,6-tetrahydropyridine (MPTP), electrophysiology]

The neurotoxin 1-methyl-4-phenyl-1,2,3,6-tetrahydropyridine (MPTP) selectively destroys dopamine (DA)-containing neurons in the ventral mesencephalon, and in particular those lo-

\footnotetext{
Received Jan. 8, 1993; revised Apr. 16, 1993; accepted Apr. 29, 1993.

We thank Mary G. Smith for technical assistance and Dr. Dennis W. Duffield for assistance in data collection in the early stages of this study. This research was supported by NIH Grant NS 23980.

Correspondence should be addressed to Dr. J. S. Schneider, Department of Neurology, MS 423, Hahnemann University School of Medicine, 15 th and Vine Streets, Philadelphia, PA 19102.

Copyright (c) 1993 Society for Neuroscience $0270-6474 / 93 / 134372-07 \$ 05.00 / 0$
}

cated in the substantia nigra pars compacta in cats (Schneider and Markham, 1986; Schneider et al., 1986) and monkeys (Burns et al., 1983; Schneider et al., 1987; German et al., 1988). The loss of neurons and the subsequent reduction in striatal DA leads to parkinson-like motor deficits in these species. This parkinsonian condition is occasionally transient in some monkeys (Eidelberg et al., 1986; Chilardi et al., 1988; Filion et al., 1988) and always transient in cats (Schneider et al., 1986; Schneider and Rothblat, 1991). Cats exposed to MPTP have been shown to recover gross motor function almost completely by 6 weeks after MPTP exposure although there is no significant recovery of dorsal striatal tissue DA levels at that time (Schneider and Rothblat, 1991).

Previously, we have shown that in symptomatic MPTP-treated cats, there is a significant loss of neuronal responses to external sensory stimuli in the caudate nucleus (Schneider, 1991). In addition, those few striatal neurons still responsive to sensory stimuli process this information in an abnormal, nonspecific manner. The loss of striatal sensory responsiveness coincides with the appearance of parkinsonian motor deficits (Schneider, 1991). Since sensory information processing appears to be an important striatal function (Schneider and Lidsky, 1981; Lidsky et al., 1985; Schneider et al., 1985), it has been suggested that perhaps the deficit in specific afferent information processing by the striatum due to extensive striatal DA depletion may at least in part lead to some of the motor manifestations of Parkinson's disease (Markham, 1987).

The purpose of the present study was to extend our previous findings (Schneider, 1991) and to investigate whether alterations in sensory information processing observed in the striatum of cats with MPTP-induced parkinsonism remain once the animals spontaneously recover gross motor function. We (Schneider and Lidsky, 1981; Lidsky et al., 1985; Schneider, 1987) and others (Kimura et al., 1984; Apicella et al., 1991; Ljungberg et al., 1991; Schwarz et al., 1992) have suggested that sensory processing is an important aspect of basal ganglia function and hence normal basal ganglia modulation of motor behavior. We would then expect that sensory responsiveness of striatal neurons would recover coincident with recovery of gross motor function. The present study examines striatal neuronal responses to peripheral polysynaptic sensory stimulation (tactile, visual, auditory) and electrical stimulation of monosynaptic afferents (pericruciate cortex and intralaminar thalamus) in symptomatic and functionally recovered MPTP-treated cats, in order to assess the extent to which peripheral versus intrinsic striatal afferents are affected by parkinsonism. This study further assesses the relationship between changes in spontaneous activity 
of striatal neurons, sensory information processing, and clinical condition.

\section{Materials and Methods}

Four adult male or female cats (2.4-3.8 kg body weight) were prepared for chronic single-unit recording as previously described (Schneider and Lidsky, 1981). All experimental procedures were performed according to established animal care and use guidelines. Briefly, under general anesthesia (sodium pentobarbital, $35 \mathrm{mg} / \mathrm{kg}$, i.p.) and aseptic conditions, a 1-cm-diameter bone flap was removed from the skull overlying the caudate nucleus and a stainless steel recording chamber (Trent Wells, Inc.) was placed in the defect and secured in place with dental acrylic. Two stainless steel tubes were also fixed to the skull with dental acrylic and used for subsequent immobilization of the head during recording sessions. A three-prong comb stimulating electrode $(0.5 \mathrm{~mm}$ exposed tip, $1 \mathrm{~mm}$ tip separation) was placed straddling the pericruciate cortex and a bipolar stimulating electrode $(0.5 \mathrm{~mm}$ exposed tip, $0.5 \mathrm{~mm}$ tip separation) was placed in nucleus (N.) centralis lateralis of the thalamus for electrical stimulation of monosynaptic afferents to the caudate nucleus.

Two weeks after surgery the cats were adapted to sitting quietly in a canvas hammock with their heads restrained. Thereafter, the cats were placed in the recording chamber with a screen containing a centrally located speaker and four red light-emitting diodes configured so as to activate a cual's visual field bilaterally. This screen was placed approximately $250 \mathrm{~cm}$ in front of the animals for the delivery of auditory and visual stimuli. Auditory stimuli (multifrequency hiss, 5 msec duration) were delivered via the centrally located loudspeaker, and visual stimuli ( 5 msec pulse duration) were delivered via the simultaneous activation of the light-emitting diodes.

For the recording of single units, glass microelectrodes filled with 3 $\mathbf{M}$ potassium citrate were passed through a guide cannula and into the brain using a Kopf miniature hydraulic microdrive. Once a unit was isolated, prestimulation spontaneous activity was measured for several minutes. The unit was then assessed for responses to sensory stimulation. Tactile responses were initially determined by gently probing the face of the animal with a blunt wooden probe. If a tactile receptive field was found, more precise measurements of the response were made using von Frey hairs placed on an electromechanical stimulator (Schneider and Lidsky, 1981). Responses to auditory and visual stimuli were then assessed, as were responses to electrical stimulation of striatal afferent structures (pericruciate cortex and N. centralis lateralis of the thalamus; single pulses, $0.5 \mathrm{~Hz}, 0.5 \mathrm{msec}$ duration). Responses to the electrical stimulation were studied at or slightly above threshold level. Mean firing rates were calculated for responses to peripheral or intrinsic stimulation and compared to mean firing rates from baseline (nonstimulation) periods. Differences of at least 2 standard deviations were considered to be responses. Since this study was primarily focusing on striatal sensory responses, responses that appeared to covary with movement were disregarded.

All cats were studied while normal, symptomatic, and functionally recovered. After baseline electrophysiological recordings were obtained (approximately 100 cells sampled), cats were administered MPTP-HCl $(5 \mathrm{mg} / \mathrm{kg}$, i.p.) for $7 \mathrm{~d}$ or until a stable parkinsonian syndrome developed. Recording of single units resumed approximately $48 \mathrm{hr}$ after the last MPTP injection. Throughout the symptomatic period, gross motor and sensorimotor behavior was assessed according to the following rating scale. For locomotion (observed in open field), $0=$ no effective locomotion; 1 = hind limbs flexed, not effectively used; 2 = slow locomotion with splayed limbs; $3=$ minor limb abnormalities, capable of effective locomotion; 4 = normal, agile locomotion. For response and orientation to external stimuli (utilizing tactile, auditory, and visual stimuli), $0=$ bilaterally unresponsive, no orienting movements; $1=$ occasional response to stimuli, wcak oricnting movements; 2 = very responsive to stimuli, readily orients. For posture, $0=$ limbs consistently held flexed (severe), $1=$ primarily hind limbs flexed (moderate), $2=$ mild flexed posture of limbs, $3=$ normal limb posture. Step-down latency was time (seconds) taken to replace forelimbs on the ground after being placed on a ledge 12 inches above floor. Single-unit recordings were obtained while behavioral assessments indicated motor deficits similar to those previously observed in parkinsonian cats (Schneider et al., 1986; Schneider and Rothblat, 1991). Recordings were obtained daily or every other day for 2-3 weeks, during which time the animals maintained stable parkinsonian symptoms. Five to six weeks after the last MPTP injection, at a time when behavioral testing indicated that the cats had significantly recovered gross motor function, recording sessions resumed and continued for approximately 3 weeks.

At the conclusion of the study, marking lesions ( $2 \mathrm{~mA}, 15 \mathrm{sec}$ duration) were made in the striatum for verification of unit recording locations and at the sites of stimulating electrodes for verification of placements. Cats were then deeply anesthetized with sodium pentobarbital and the head implant was removed. The animals were then overdosed with sodium pentobarbital $(150 \mathrm{mg} / \mathrm{kg}$, i.v.) and the brain was removed fresh and placed in cold phosphate-buffered saline. The caudate nucleus contralateral to the recording site was dissected into dorsal lateral (DL), dorsal medial, ventral lateral, and ventral medial regions and, together with the nucleus accumbens, was sampled for determination of catecholamine and metabolite levels by high-performance liquid chromatography (HPLC) with electrochemical detection (Schneider and Rothblat, 1991). The remainder of the brain was submersion fixed in $4 \%$ paraformaldehyde for at least $48 \mathrm{hr}$ and then placed in $30 \%$ sucrose for another $48 \mathrm{hr}$. Sections $60 \mu \mathrm{m}$ thick were cut frozen on a sliding microtome and stained with cresyl violet. Electrolytic lesions were localized by the Prussian blue reaction and electrode penetrations were reconstructed to determine the location of recorded units.

\section{Results}

\section{Behavior and tissue DA levels}

All cats given MPTP displayed motor deficits similar to those described previously (Schneider et al., 1986). That is, all cats were rigid, severely akinetic, froze during attempted movement, and were unresponsive to peripheral sensory stimuli. Nutrition and hydration were administered by hand while the animals were severely parkinsonian. Measures of posture, spontaneous locomotion, and step-down latency indicated severe akinesia and motor impairment in the first 2-3 weeks following MPTP administration. The extent of the motor deficits is shown in Figure 1.

Six weeks after the last MPTP injection, motor function appeared to have returned to normal levels (Fig. 1), as did the animals' responses to external stimuli. There were no significant differences between the behavioral measures obtained when the animals were normal and when they appeared to have spontaneously recovered $(p>0.05)$.

MPTP produced a significant loss of DL caudate DA levels. DA measured in the recovered cats was $1.05 \mu \mathrm{g} / \mathrm{gm}$ tissue $( \pm 0.88)$, approximately $92 \%$ below DA levels previously reported in normal cats. The DA levels seen in recovered cats used in this study are in agreement with previous studies (Schneider and Rothblat, 1991). Cats were not killed while symptomatic, but previous studies (Schneider and Rothblat, 1991) have shown that DL caudate DA levels in symptomatic animals are $0.12 \mu \mathrm{g} / \mathrm{gm}$ tissue $( \pm 0.14), 98 \%$ below normal levels.

\section{Striatal units-spontaneous activity}

All units analyzed ( $n=804)$ were located in the caudate nucleus, primarily in the DL region (Fig. 2). In normal cats, DL caudate neurons $(n=203)$ had spontaneous mean firing rates of 2.25 spikes/sec (Fig. 3). The spontaneous firing rate increased significantly to a mean of 6.20 spikes $/ \mathrm{sec}(p<0.001, n=292)$ in symptomatic MPTP-treated cats. When the cats recovered gross motor behavior, spontaneous activity of DL caudate nucleus neurons was 2.26 spikes/sec $(n=309)$, not significantly different from normal $(p>0.05)$ but significantly less than the mean spontaneous firing rate observed when animals were symptomatic for a motor disorder $(p<0.001)$. The distribution of spontaneous firing rates (Fig. 3) demonstrates the increase in the number of neurons with higher spontaneous rates and the decrease in the number of neurons with the slowest spontaneous 


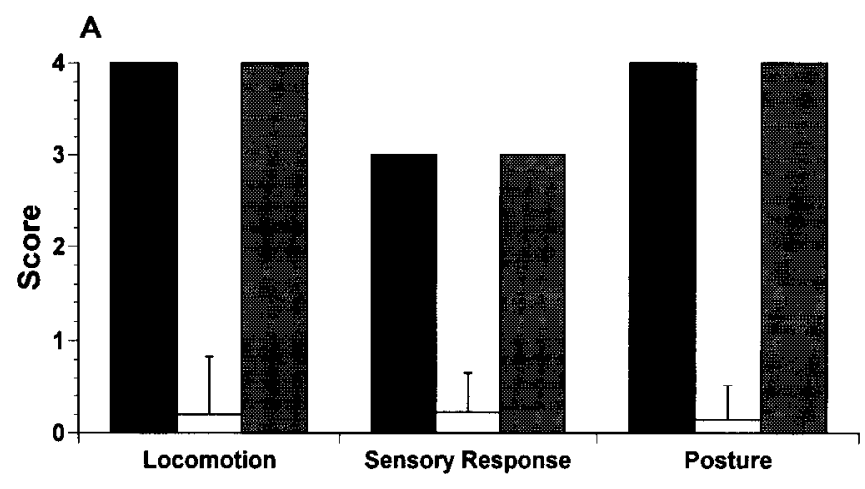

B

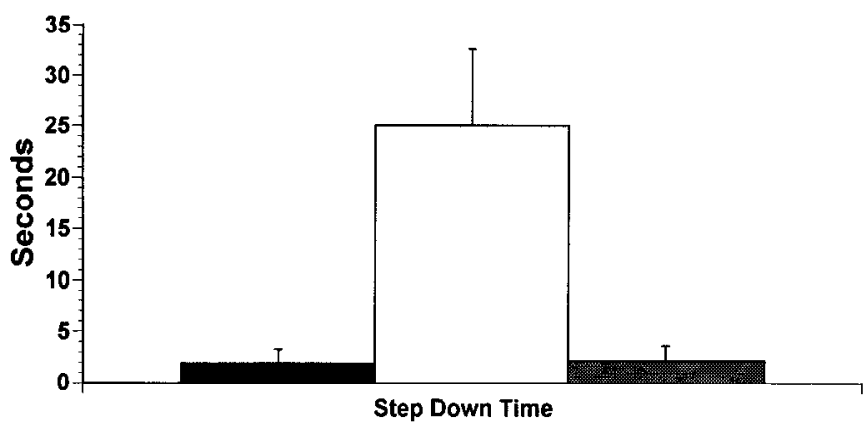

Normal

$\square$ Symptomatic

Recovered

Figure 1. Motor function in MPTP-treated cats as assessed by rating scale $(A)$ and step-down latency $(B)$. Data was calculated as mean scores $( \pm S D$ ) for all cats obtained during a total of 40 observations during the normal, 34 observations during the symptomatic, and 40 observations during the recovered periods. $A$, During the first 2-3 weeks following MPTP exposure all cats had significantly decreased spontaneous locomotion, were unresponsive to visual, tactile, and auditory stimulation, and maintained a flexed, rigid posture (see Materials and Methods for rating scale). Six weeks after MPTP administration, all cats appeared normal in respect to locomotion, sensory responsiveness, and posturc. $B$, All cats took significantly longer than normal, during the first 2-3 weeks following MPTP administration, to replace their forelimbs on the ground after being placed on a ledge 12 inches above the floor. Six weeks after MPTP, step-down latencies were again within normal limits.

rates in symptomatic animals as compared to the normal and functionally recovered animals.

\section{Striatal units-sensory responsiveness}

Sensory responsive units were found in almost all electrode penetrations in the normal and recovered conditions. There was no indication of a distinct somatotopy with regard to tactile responsive units. Facial tactile fields were found at nearly all recording sites (from approximately A17.5-A15.5, and L5.0L7.0; Berman and Jones, 1982). Of the neurons tested in the normal condition, $17 \%$ (57 of 339 ) responded to tactile stimulation of the face, $5.4 \%$ ( 15 of 276 ) responded to auditory stimulation, and $4.5 \%$ ( 8 of 179) had visual responses. Tactile receptive ficlds werc typically small $(77 \%)$, located on one side of the face (74\%), and responded to one type of sensory stimuli $(88 \%)$ (Table 1). Receptive field sizes were defined as follows: small $=$ discrete or isolated area on the face (e.g., front muzzle area, adjacent to the midline or the vibrissa field); medium = combinations of two or more discrete fields (e.g., muzzle area plus vibrissa or chin and lower jaw area) encompassing less than the whole side of the face; large $=$ the whole side of the face or entire face. The optimal stimulus for eliciting a tactile response (e.g., brushing and/or punctate skin indentation) and the laterality of receptive fields (unilateral or bilateral receptive field) were similar to those described previously (Schneider and Lidsky, 1981) in studies of sensory responsiveness of striatal neurons in normal cats (Fig. 4, Table 1). A brushing stimulus was defined as a rapid sweep or movement of the hair or vibrissa, and punctate stimulation was defined as indentation of the skin.

In symptomatic MPTP-treated cats, sensory responsiveness of DL caudate neurons was significantly less than that observed in the normal condition. Seven percent (17 of 242) responded to tactile stimulation of the face $\left(\chi^{2}=8.82 ; p<0.005\right), 2.0 \%$ ( 4 of 198 ) responded to auditory stimulation $\left(\chi^{2}=2.66 ; p>\right.$ 0.05 ), and no cells ( 0 of 146) responded to visual stimulation $\left(\chi^{2}=4.96 ; p<0.05\right)$. Of the units that did respond to tactile stimulation, a greater number responded to bilateral stimulation ( $59 \%$ in symptomatic vs $26 \%$ in normal cats), had large receptive fields ( $53 \%$ in symptomatic vs $9 \%$ in normal cats), and responded to both punctate and brushing stimuli (54\% in symptomatic vs $12 \%$ in normal cats) (Table 1 , Fig. 4 ).

After the cats had spontaneously recovered gross motor function, DL caudate sensory responsiveness was similar to that seen in normal animals. Fifteen percent (49 of 328) of the units tested for tactile responsiveness in functionally recovered animals responded to tactile stimulation of the face. This was a significant increase above the percentage of tactile responsive neurons recorded when animals were symptomatic $\left(x^{2}=6.16\right.$; $p<0.05$ ) but not significantly different from the percentage of tactile responsive units recorded when animals were normal $\left(\chi^{2}\right.$ $=0.21 ; p>0.05)$. In functionally recovered animals, $4.3 \%$ of units tested responded to visual stimulation $\left(\chi^{2}=0.58 ; p>\right.$ 0.05 compared to normal) and $2.2 \%$ responded to auditory stimulation $\left(\chi^{2}=1.60 ; p>0.05\right.$ compared to normal). Response
Figure 2. Caudate electrode penetrations in normal $(A)$, symptomatic $(B)$, and recovered $(C)$ conditions. $A-C$ are each a composite from all cats recorded from in each condition. solid circles, squares, and triangles denote locations of cells with somatosensory, visual, and auditory responses, respectively. Lines denote locations of nonresponsive units. Similar electrode penetrations were made in all conditions. Note the decrease in the number of sensory responsive units in symptomatic animals and the return of sensory responsiveness in recovered cats.
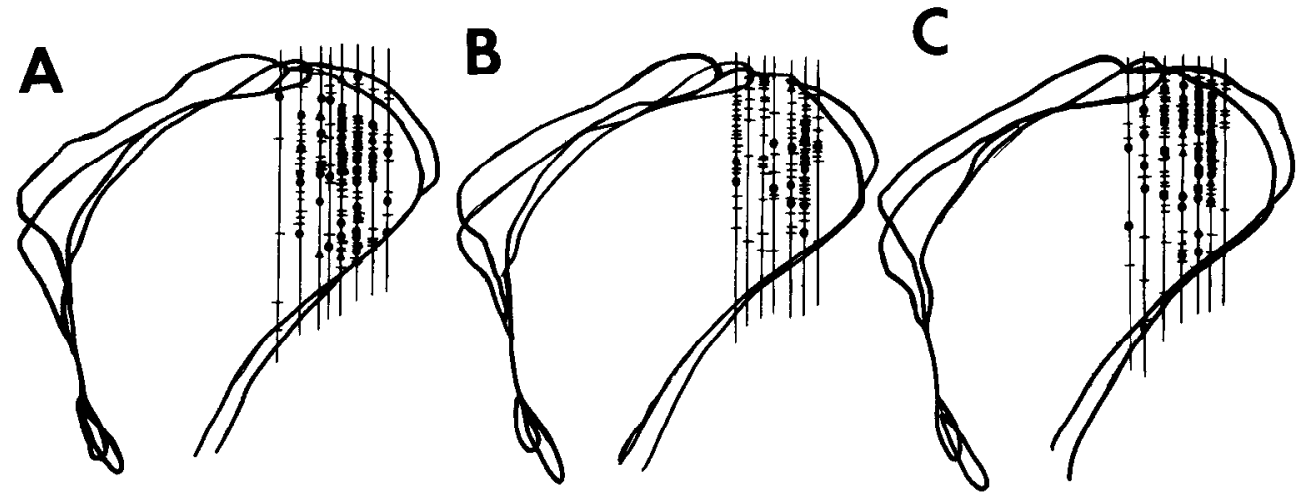


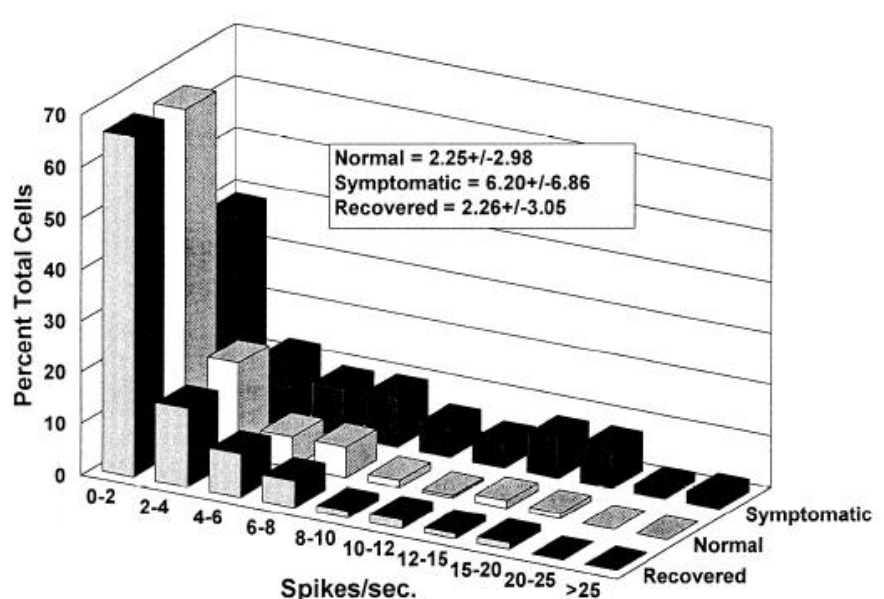

Figure 3. Distribution of spontaneous firing rates of neurons recorded in the DL caudate nucleus in normal, symptomatic, and recovered MPTP-treated cats. Note the decrease in the percentage of the slowest firing neurons and the increase in the percentage of neurons with fast spontaneous rates $(>10$ spikes $/ \mathrm{sec})$ in symptomatic animals. The distribution of spontaneous firing rates appeared normal in recovered animals.

characteristics of tactile-responsive neurons in recovered cats were not significantly different from normal (Table 1, Fig. 4): $61 \%$ of units tested had small receptive fields; $25 \%$ had bilateral receptive fields; $15 \%$ responded to both punctate and brushing stimuli.

\section{Responses to electrical stimulation}

Stimulation of the pericruciate cortex and N. centralis lateralis of the thalamus produced responses in DL caudate neurons characterized by either an initial facilitation (E) or initial decrement in firing (I). In normal cats, $43 \%$ (71 of 163) of cells tested responded in some manner to cortical stimulation. Eightythree percent of these responded with an initial $\mathrm{E}$ while $17 \%$ responded with an initial I. Twenty-seven percent of cells tested in normal animals responded to thalamic stimulation: $82 \%$ responded with an initial $\mathrm{E}$ and $18 \%$ responded with an initial $\mathrm{I}$. The mean latencies and stimulation thresholds for these $\mathrm{E}$ and I responses are shown in Table 2.

In symptomatic animals, the percentage of cells responding to electrical stimulation of either the cortex or thalamus increased significantly above that observed in normal animals. Sixty-eight percent of cells tested responded to cortical stimulation $\left(\chi^{2}=5.32 ; p<0.05\right)$, and $46 \%$ responded to thalamic stimulation $\left(\chi^{2}=8.36 ; p<0.01\right)$. The overall percentage of cells with an initial $\mathrm{E}$ or an initial I did not significantly change (79\% E and $21 \%$ I for cortex stimulation, $78 \% \mathrm{E}$ and $22 \%$ I for thalamic stimulation), nor did the mean latency of responses (Table 2). There were only minor differences in the latency distributions for responses to cortical or thalamic stimulation across the three conditions (Fig. 5). However, the mean threshold current necessary to elicit cortical or thalamic responses significantly decreased in symptomatic animals.

In functionally recovered cats, striatal responses to electrical stimulation of cortical and thalamic afferents resembled those observed in normal animals. Forty-one percent of cells tested responded to cortical stimulation and $27 \%$ responded to thalamic stimulation, neither significantly different from normal ( $p$ $>0.05$ ), but significantly lower than the percentages observed in symptomatic animals $\left(\chi^{2}=9.47, p<0.01\right.$ for cortical stim-
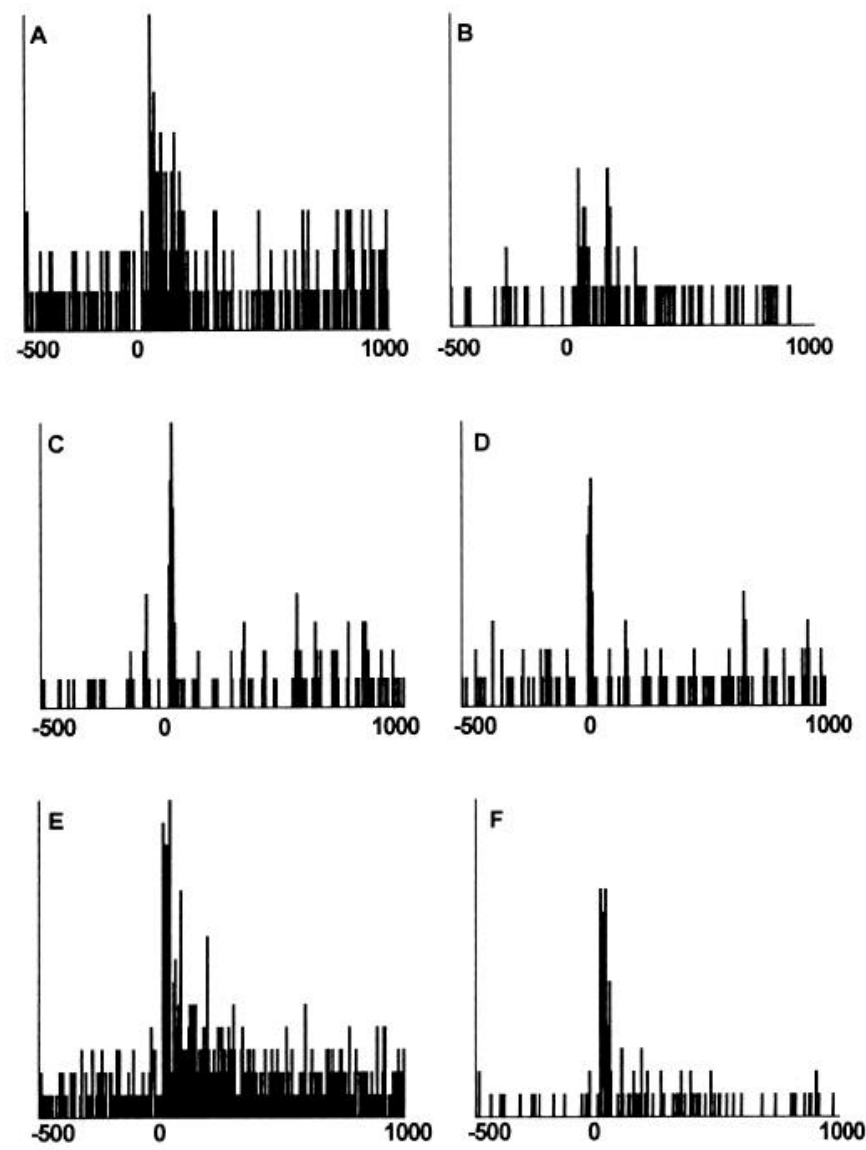

Time (msec.)

Figure 4. Specificity of caudate neuronal responses to tactile stimulation of the face in normal $(A, B)$, symptomatic $(C, D)$, and recovered $(E, F)$ MPTP-treated cats. Peristimulus-time histograms show caudate unit responses to stimulation of the face in the front, upper muzzle region $(A, C, E)$ and the vibrissa field $(B, D, F)$ in cells with large tactile receptive fields. In the normal animal, units responded with a greatermagnitude response the closer the stimulus was to the midline. When the animal was symptomatic for MPTP-induced parkinsonism, stimulation anywhere on the face within the receptive field for the unit elicited approximately equal responses. The ability to encode stimulus location on the face using the midline as a reference point was lost or significantly diminished in symptomatic animals. When animals recovered from MPTP-induced parkinsonism, response specificity (i.e., "orocentric" encoding of stimulus location on the face) returned to normal.

ulation; $\chi^{2}=9.06, p<0.01$ for thalamic stimulation). The percentage of cortical responses with initial E (79\%) or initial I $(21 \%)$ in recovered cats was not significantly different from that observed in symptomatic or normal cats. The same was true for responses to thalamic stimulation in recovered animals $(76 \%$ initial $\mathrm{E}$ and $24 \%$ with initial I). The threshold to elicit a response remained significantly decreased from normal for both response types (E and I) for cortical stimulation $(p<0.01)$ and for thalamic responses with an initial I ( $p<0.05)$ (Table 2).

Responses to electrical stimulation were also subdivided into response types based on presence or absence of rebound facilitations (E) and/or decrements in firing (I) after the initial response. There were more pure E and E-I sequence-type responses in normal animals versus symptomatic or recovered animals but this did not reach statistical significance (Fig. 5). Overall, there was little change in response type elicited from 
Table 1. Characteristics of tactile responsive units in the DL caudate

\% Responsive sample (no. of cells)

\begin{tabular}{lcll} 
& \multicolumn{3}{l}{$\%$ Responsive sample (no. of cells) } \\
\cline { 2 - 4 } & Normal & Symptomatic & Recovered \\
\hline Optimal stimulus & & & \\
Punctate & $39 \%(20 / 51)$ & $15 \%(2 / 13)$ & $28 \%(11 / 40)$ \\
Brushing & $49 \%(25 / 51)$ & $31 \%(4 / 13)$ & $58 \%(23 / 40)$ \\
Both & $12 \%(6 / 51)$ & $54 \%(7 / 13)$ & $15 \%(6 / 40)$ \\
Receptive field type & & & \\
Contralateral & $65 \%(35 / 54)$ & $29 \%(5 / 17)$ & $60 \%(29 / 48)$ \\
Ipsilateral & $9 \%(5 / 54)$ & $12 \%(2 / 17)$ & $15 \%(7 / 48)$ \\
Bilateral & $26 \%(14 / 54)$ & $59 \%(10 / 17)$ & $25 \%(12 / 48)$ \\
Receptive field size & & & \\
Large & $9 \%(5 / 57)$ & $53 \%(9 / 17)$ & $18 \%(9 / 49)$ \\
Medium & $14 \%(8 / 57)$ & $29 \%(5 / 17)$ & $20 \%(10 / 49)$ \\
Small & $77 \%(44 / 57)$ & $18 \%(3 / 17)$ & $61 \%(30 / 49)$ \\
\hline
\end{tabular}

cortical or thalamic stimulation based on the motor condition of the animal. There was also no significant difference in the duration of either initial or rebound I periods between the three conditions (169 msec \pm 95 in normal cats, $143 \mathrm{msec} \pm 53$ in symptomatic cats, $163 \mathrm{msec} \pm 85$ in recovered cats).

\section{Discussion}

The present results support our previous findings that DA depletion in the DL caudate results in parkinsonian motor symptoms and a coincident loss of sensory responsiveness of neurons in this area (Schneider, 1991). The alterations in sensory responsiveness in this and the previous study (Schneider, 1991) were manifested as changes in both the number and quality of striatal sensory responses. This finding is similar to that reported by Filion et al. (1988), where a loss of specificity in globus pallidus (GP) neuronal responsiveness was found in MPTPtreated monkeys. In contrast to the present results, Filion et al. found an increase in the number of sensory responsive units in
Table 2. Parameters of responses to afferent stimulation [mean (SD)]

\begin{tabular}{|c|c|c|c|}
\hline Response type & Normal & Symptomatic & Recovered \\
\hline \multicolumn{4}{|l|}{ Cortex-initial E } \\
\hline Latency (msec) & $11.9(5.6)$ & $12.8(13.1)$ & $10.8(4.2)$ \\
\hline Threshold (mA) & $2.1(1.2)$ & $1.4(0.9)^{* * *}$ & $1.5(0.9) \neq$ \\
\hline \multicolumn{4}{|l|}{ Cortex-initial I } \\
\hline Latency & $26.1(11.6)$ & $28.9(11.5)$ & $25.7(13.9)$ \\
\hline Threshold & $2.2(1.1)$ & $1.5(0.8)^{*}$ & $1.6(0.9)$ \\
\hline \multicolumn{4}{|l|}{ Thalamus-initial E } \\
\hline Latency & $9.9(4.6)$ & $11.5(13.6)$ & $13.1(14.8)$ \\
\hline Threshold & $1.5(1.0)$ & $1.3(0.6)$ & $1.6(0.7) \dagger$ \\
\hline \multicolumn{4}{|l|}{ Thalamus-initial I } \\
\hline Latency & $30.6(10.1)$ & $35.5(15.6)$ & $31.2(14.8)$ \\
\hline Threshold & $2.2(0.9)$ & $1.3(0.6)^{* * *}$ & $1.3(0.4) \ddagger$ \\
\hline
\end{tabular}

their monkcys. One possible explanation for the discrepancy between this and our present findings is that monkeys used in the previous work may not have been as severely parkinsonian as the cats used during the symptomatic phase of the present study. Also, the extent of DA depletion in the monkeys was not quantified. Sensory information processing may be altered in different ways depending upon the severity and localization of the DA depletion. Additionally, differences in the findings between these two studies might be explained by the differences in recording sites (GP vs caudate nucleus) and different types of sensory stimuli used to elicit responses. The present findings, however, are supported by recent work by Aosaki et al. (1992) in which a profound decrease in context-dependent sensory responses was found in the striatum of MPTP-treated monkeys.

The present results also extend previous work from this lab-
Figure 5. Response of caudate neurons to electrical stimulation of pericruciate cortex $(A, B)$ and $\mathrm{N}$. centralis lateralis $(C, D)$ in normal, symptomatic, and recovered MPTP-treated cats. There were no apparent changes in the latency distributions (in $\mathrm{msec}$ ) for responses to cortical $(A)$ or thalamic $(C)$ stimulation across conditions. There were also few differences in the response characteristics across conditions $(B, D)$ with the cxception of a trend toward more pure excitatory responses from cortex stimulation $(B)$ occurring in normal animals. Abbreviations: $E$, initial facilitory response; $E I$, facilitation followed by a decrease in activity; $E I E$, facilitation followed by a decrease in activity followed by a secondary facilitation; $I$, initial decrement in activity; $I E$, initial decrement followed by a facilitation in activity.
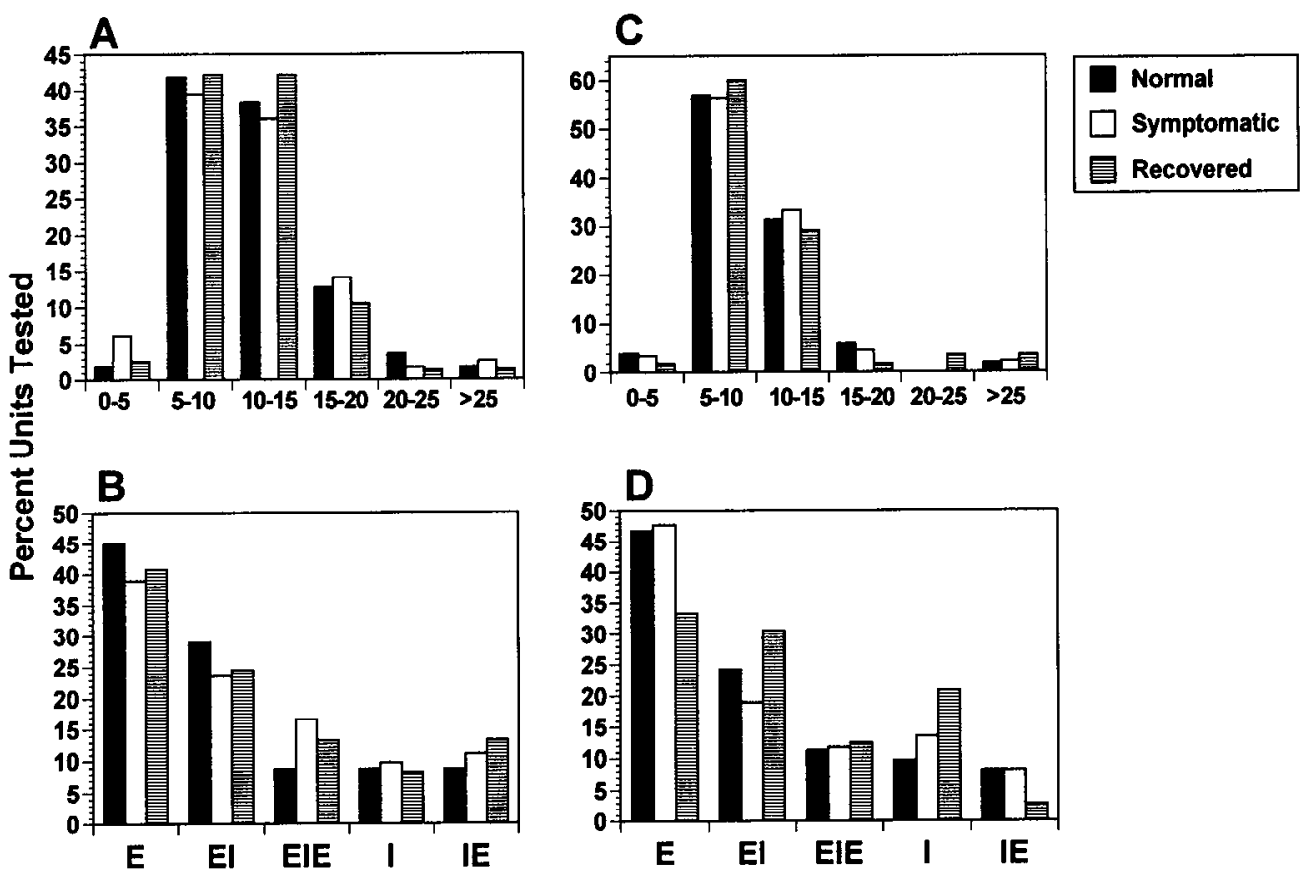
oratory (Schneider, 1991) by demonstrating that once a parkinsonian cat recovers gross motor function, there is a coincident normalization of both the quantity and quality of sensory information processed by DL striatal neurons. This further suggests that the processing of sensory information by the striatum may importantly influence motor function.

We have previously reported that motor recovery in MPTPtreated cats is accomplished without a significant recovery of tissue DA levels in the DL caudate (Schneider and Rothblat, 1991). Although tissue DA levels in the DL caudate of functionally recovered cats remain depleted (approximately 95\%) extracellular fluid (ECF) concentrations of DA are not as severely depleted and recover to approximately $50 \%$ of normal levels (DiStefano and Schneider, 1991). Therefore, it is possible that the level of ECF D $\Lambda$ in the DL caudate in recovered cats may by sufficient to normalize the physiological functioning of intrinsic neurons in this region, resulting in recovery of sensory responsiveness as well as motor functioning (Schneider et al., 1992).

The present study also found an increase in responsiveness and decrease in the stimulation current thresholds needed to elicit responses of DL caudate neurons to electrical stimulation of monosynaptic cortical and thalamic afferents in symptomatic animals. In the same animals, a decrease in responsiveness to peripheral sensory stimuli was found. There are several possible explanations for these seemingly dichotomous findings. Anatomical studies have shown that DAergic terminals synapse primarily on the proximal shafts of spines of caudate medium spiny output neurons while glutamatergic inputs from cortex (and most likely thalamus) synapse primarily on the distal ends of these spines (Smith and Bolam, 1990). This suggests that DAergic inputs may be able to modulate excitatory cortical/ thalamic inputs. The loss of DAergic input, which appears to be inhibitory at least on a subpopulation of striatal neurons (Herrling and Hull, 1980), might allow more striatal neurons to respond to stimulation of the cortex or thalamus and perhaps lower the stimulation threshold needed to elicit a response, as we observed in symptomatic animals. In recovered animals, a return of inhibitory modulation of striatal neurons (via increased ECF concentrations of DA) might have contributed to the return to relatively normal levels of striatal responsiveness to stimulation of monosynaptic inputs. This might suggest, then, that the decrease in peripheral (i.e., polysynaptic) sensory responsiveness seen in the caudate nucleus in symptomatic animals may at least in part be mediated extrastriatally.

With extensive loss of DA, we show, as have others (Johnson et al., 1983; Nisenbaum et al., 1986), that there appears to be a concomitant increase in the spontaneous activity of a population of striatal neurons. Such a change in spontaneous activity has been suggested to occur in GP-projecting striatal enkephalin/ GABAergic neurons (Albin et al., 1989). This change in striatal activity may lead to a decrease in the spontaneous activity of some GP neurons, and a consequent disinhibition of the subthalamic nucleus (Penney and Young, 1983; Gerfen, 1992). Increased excitatory output from the subthalamic nucleus to the entopeduncular nucleus (ENTO) could then ultimately result in an increased inhibitory drive upon thalamic target neurons (both intralaminar neurons projecting primarily to the striatum and neurons projecting to the cortex). These same thalamic areas [ventral anterior/ventral lateral and intralaminar (central median/parafascicular and central lateral, and reticular)] also receive inputs from various sensory systems such as the dorsal columns (McClung and Dafny, 1980; Hirai and Jones, 1988; Padel and Relova, 1991; Mackel and Miyashita, 1992) and the reticular formation (Pare et al., 1988; Steriade et al., 1988). The intralaminar nuclei additionally receive significant inputs from the superior colliculus (Grunberg and Krauthamer, 1992) that convey trigeminal and other sensory signals to these nuclei. An increase in ENTO activity consequent to extensive striatal DA loss could affect the processing of these sensory signals as they pass through the thalamus and perhaps ultimately also result in disfacilitation of cortical neurons that might send sensory signals to the striatum. A decrease in sensory information processing within the thalamus may then affect direct thalamic sensory inputs to the striatum as well as perhaps inputs relayed via the cortex. This may contribute to the sensory processing deficits observed in the striatum, to motor deficits seen in MPTP-induced parkinsonism, and perhaps even to some sensorimotor deficits seen in human Parkinson disease. Removal of excess inhibitory influences upon the thalamus (and indirectly upon the cortex) could allow more normal processing of sensory information as seems to occur in motor-recovered animals.

\section{References}

Albin RL, Young AB, Penney JB (1989) The functional anatomy of basal ganglia disorders. I rends Neurosci 12:366-375.

Aosaki T, Ishida A, Watanabe K, Imai H, Graybiel AM, Kimura M (1992) Effects of dopaminergic agents on the tonically active neurons of the striatum in hemi-parkinsonian monkeys. Soc Neurosci Abstr 18:693.

Apicella P, Scarnati E, Schultz W (1991) Tonically discharging neurons of monkey striatum respond to preparatory and rewarding stimuli. Exp Brain Res 84:672-675.

Berman AJ, Jones EG (1982) The thalamus and basal tclencephalon of the cat: a cytoarchitectonic atlas with stereotaxic coordinates. Madison, WI: University of Wisconsin.

Burns RS, Chiueh CC, Markey SP, Ebert MH, Jacobowitz DM, Kopin IJ (1983) A primate model of parkinsonism: selective destruction of dopaminergic neurons in the pars compacta of the substantia nigra by $N$-methyl-4-phenyl-1,2,3,6-tetrahydropyridine. Proc Natl Acad Sci USA 80:4546-4550.

Chilardi MF, Bodis-Wollner I, Onofrj MC, Glover A, Marx MS (1988) MPTP-treated monkeys: a model for Parkinson's disease? Electrophysiological results of pharmacological manipulations. In: Neurodegenerative disorders: the role played by endotoxins and xenobiotics (Nappi G, Hornykiewicz O, Fariello RG, Agnoli A, Klawons H, eds), pp 93-1 10. New York: Raven.

DiStefano L III, Schncider JS (1991) Motor recovery in MPTP-treated cats is accompanied by partial recovery of extracellular dopamine levels in dorsal lateral caudate nucleus. Soc Neurosci Abstr 17:855.

Eidelberg E, Brooks BA, Morgan WW, Walden JG, Kokemoor RH (1986) Variability and functional recovery in the $N$-methyl-4-phenyl$1,2,3,6$-tetrahydropyridine model of parkinsonism in monkeys. Neuroscience 18:817-822.

Filion M, Tremblay L, Bedard PJ (1988) Abnormal influences of passive limb movement on the activity of globus pallidus neurons in parkinsonian monkeys. Brain Res 444:165-176.

Gerfen CR (1992) The neostriatal mosaic: multiple levels of compartmental organization. Trends Neurosci 15:133-139.

German DC, Dubach M, Askari S, Speciale SG, Bowden DM (1988) 1-Methyl-4-phenyl-1,2,3,6-tetrahydropyridine-induced parkinsonian syndrome in macaca fascicularis: which midbrain dopaminergic neurons are lost? Neuroscience 24:161-174.

Grunberg BS, Krauthamer GM (1992) Sensory responses of intralaminar thalamic neurons activated by the superior colliculus. Exp Brain Res 88:541-550.

Herrling PL, Hull CD (1980) Iontophoretically applied dopamine depolarizes and hyperpolarizes the membrane of cat caudate neurons. Brain Res 192:441-462.

Hirai T, Jones EG (1988) Segregation of lemniscal inputs and motor cortex outputs in cat ventral thalamic nuclei: application of a novel technique. Exp Brain Res 71:329-344. 
Johnson SW, Palmer MR, Freedman R (1983) Effects of dopamine on spontaneous and evoked activity of caudate neurons. Neuropharmacology 22:843-851.

Kimura M, Rajkowski J, Evarts E (1984) Tonically discharging putamen neurons exhibit set-dependent responses. Proc Natl Acad Sci USA 81:4998-5001.

Lidsky TI, Manetto C, Schneider JS (1985) Consideration of sensory factors involved in motor functions of the basal ganglia. Brain Res Rev 9:133-146.

Ljungberg T, Apicella P, Schultz W (1991) Responses of monkey midbrain dopamine neurons during delayed alternation performance. Brain Res 567:337-341.

Mackel R, Miyashita E (1992) Dorsal column input to thalamic VL neurons: an intracellular study in the cat. Exp Brain Res 88:551-559.

Markham CH (1987) The "motor" vs. "sensory" enigma in Parkinson's disease. In: Basal ganglia and behavior: sensory aspects of motor functioning (Schneider JS, Lidsky TI, eds), pp 161-168. Lewiston, NY: Huber.

McClung RE, Dafny N (1980) The parafascicular nucleus of thalamus exhibits convergence input from the dorsal raphe and the spinal tract of the trigeminal nerve. Brain Res 197:525-531.

Nisenbaum ES, Stricker EM, Zigmond MJ, Berger TW (1986) Longterm effects of dopamine-depleting brain lesions on spontaneous activity type II striatal neurons: relation to behavioral recovery. Brain Res 398:221-230.

Padel Y, Relova JL (1991) Somatosensory responses in the cat motor cortex. I. Identification and course of an afferent pathway. J Neurophysiol 66:2041-2058.

Pare D, Smith Y, Parent A, Steriade M (1988) Projections of brainstem core cholinergic and non-cholinergic neurons of cat to intralaminar and reticular thalamic nuclei. Neuroscience 25:69-86.

Penney JB, Young AB (1983) Speculation on the functional anatomy of basal ganglia disorders. Annu Rev Neurosci 6:73-94.

Schneider JS (1987) Basal ganglia-motor influences: role of sensory gating. In: Basal ganglia and behavior: sensory aspects of motor functioning (Schneider JS, Lidsky TI, eds), pp 103-122. Lewiston, NY: Huber.
Schneider JS (1991) Responses of striatal neurons to peripheral sensory stimulation in symptomatic MPTP-exposed cats. Brain Res 544: 297-302.

Schneider JS, Lidsky TI (1981) Processing of somatosensory information in striatum of behaving cats. J Neurophysiol 45:841-851.

Schneider JS, Markham CH (1986) Neurotoxic effects of $N$-methyl4-phenyl-1,2,3,6-tetrahydropyridine (MPTP) in the cat. Tyrosine hydroxylase immunohistochemistry. Brain Res 373:258-267.

Schneider JS, Rothblat DS (1991) Neurochemical evaluation of the striatum in symptomatic and recovered MPTP-treated cats. Neuroscience 44:421-429.

Schneider JS, Levine MS, Hull CD, Buchwald NA (1985) Development of somatosensory responsiveness in the basal ganglia in awake cats. J Neurophysiol 54:143-154.

Schneider JS, Yuwiler A, Markham CH (1986) Production of a parkinson-like syndrome in the cat with $N$-methyl-4-phenyl-1,2,3,6-tetrahydropyridine (MPTP): behavior, histology and biochemistry. Exp Neurol 91:293-307.

Schneider JS, Yuwiler A, Markham CH (1987) Selective loss of subpopulations of ventral mesencephalic dopaminergic neurons in the monkey following exposure to MPTP. Brain Res 411:144-150.

Schneider JS, Rothblat DS, DiStephano L (1992) Contributions of reuptake inhibition and dopamine denervation to volume transmission of dopamine in the striatum in normal and MPTP-treated cats. Soc Neurosci Abstr 18:693.

Schwarz M, Block F, Topper R, Sontag K, Noth J (1992) Abnormalities of somatosensory evoked potentials in the quinolinic acid model of Huntington's disease: evidence that basal ganglia modulate sensory cortical input. Ann Neurol 32:358-364.

Smith AD, Bolam JP (1990) Neural network of the basal ganglia as revealed by the study of synaptic connections of identified neurons. Trends Neurosci 13:259-265.

Steriade M, Pare D, Parent A, Smith Y (1988) Projections of cholinergic and non-cholinergic neurons of the brainstem core to relay and associational thalamic nuclei in the cat and macaque monkey. Neuroscience 25:47-67. 